Article

\title{
Analysing Clusters of Consumers Who Use Medicinal and Aromatic Plant Products
}

\author{
Roxana-Larisa Cadar ${ }^{1}$, Antonio Amuza ${ }^{2}$, Diana Elena Dumitras ${ }^{3}{ }^{D}$, Mihaela Mihai ${ }^{4, *}$ \\ and Cristina Bianca Pocol ${ }^{1, *(D)}$
}

1 Department of Animal Production and Food Safety, University of Agricultural Sciences and Veterinary Medicine of Cluj Napoca, 400372 Cluj-Napoca, Romania; roxana.cadar@usamvcluj.ro

2 Department of Sociology and Social Work, University of Bucharest, 061119 Bucharest, Romania; amuza.antonio@gmail.com

3 Department of Economic Sciences, University of Agricultural Sciences and Veterinary Medicine of Cluj Napoca, 400372 Cluj-Napoca, Romania; ddumitras@usamvcluj.ro

4 Department of Transversal Competences, University of Agricultural Sciences and Veterinary Medicine of Cluj Napoca, 400372 Cluj-Napoca, Romania

* Correspondence: mihaela.mihai@usamvcluj.ro (M.M.); cristina.pocol@usamvcluj.ro (C.B.P.)

Citation: Cadar, R.-L.; Amuza, A.; Dumitras, D.E.; Mihai, M.; Pocol, C.B. Analysing Clusters of Consumers Who Use Medicinal and Aromatic Plant Products. Sustainability 2021, 13, 8648. https://doi.org/10.3390/ su13158648

Academic Editors: Giovanni Sogari and Irina Dolgopolova

Received: 6 July 2021

Accepted: 30 July 2021

Published: 3 August 2021

Publisher's Note: MDPI stays neutral with regard to jurisdictional claims in published maps and institutional affiliations.

Copyright: (c) 2021 by the authors. Licensee MDPI, Basel, Switzerland. This article is an open access article distributed under the terms and conditions of the Creative Commons Attribution (CC BY) license (https:// creativecommons.org/licenses/by/ $4.0 /)$.

\begin{abstract}
The trend towards health and environmental protection has led to an increase in the consumption of medicinal and aromatic plant (MAP) products. The market for MAP products is influenced by consumer behaviour and therefore the aim of this study was to identify consumer segments that use MAP products for phytotherapeutic, cosmetic and personal care purposes according to their perceptions, attitudes and consumption habits and possible correlations between consumption of MAP products and interest in a healthy lifestyle and sustainable behaviour. Data collection was performed by administering a questionnaire to Cluj-Napoca residents. The final sample consisted of two groups of MAP consumers: the first with 231 respondents who use these products for phytotherapeutic purposes, the second group-with 297 respondents who use them as cosmetic and personal care products. The collected data were statistically analysed using the $k$-means clustering model, resulting in two distinct clusters in both consumer groups: cluster 1, the "Curious", and Cluster 2, the "Knowledgeable". For the consumers of the second cluster, consumption was positively correlated with healthcare and environmental protection, while they exhibited a growing interest in environmentally certified MAP products. The results obtained contribute to a better understanding of the MAP products consumption behaviour while tackling the practical implications for stakeholders in the pharmaceutical and cosmetics industry through the development and innovation of products tailored to consumer needs.
\end{abstract}

Keywords: medicinal and aromatic plants; phytotherapeutic products; cosmetic products; consumption behaviour; consumer segmentation

\section{Introduction}

It is indeed since ancient times that people have used medicinal and aromatic plants (MAPs) to improve their quality of life, both to treat various health problems [1,2] and to care for and improve overall physical appearance [3]. As a trend in the current pandemic context, attention has also been drawn towards the antiviral potential of plant-based preparations and their effectiveness in supporting the human immune system against infections [4].

MAPs are plant raw materials rich in secondary metabolites [5] and play various functions in the growth and nourishment of the body, in pigmentation, while exhibiting insecticidal, antifungal and antibacterial action [6,7] as well as protecting against oxidative stress and UV radiation [8]. However, they both entail benefits as well as toxicity of products derived from medicinal and aromatic plants $[9,10]$. 
By using MAPs as raw materials, a series of intermediate or final products can be obtained, such as allopathic medicines, phytotherapeutic products, botanical supplements, cosmetics and personal care products, paints and dyes, pesticides, etc. [11-13].

In recent years, the emergence of a growing consumer interest in a healthy lifestyle and sustainable behaviour has become apparent, while attention has been granted to the impact that consumer purchasing decisions might have on their health and the environment $[14,15]$ In terms of lifestyle, consumers who seek to be treated in a holistic and natural way and improve well-being, prevent and/or treat certain conditions, use traditional, alternative or complementary medicine, including herbal medicine, also called phytotherapy, as well as natural cosmetics and personal care products $[14,16-20]$ because such products containing plant ingredients are considered safe and effective $[10,21]$. Medicinal plants, traditionally used for thousands of years, are present in herbal preparations and in herbal medicine overall as a popular form of traditional, alternative and complementary medicine [20,22]. In Romania, herbal medicines are regulated under European Directive 2001/83/EC, including those in the list of prescription medicines and non-prescription medicines sold with medical claims [22]. There is also growing interest in protecting the environment, endangered species, increasing demand for quality plant raw materials obtained sustainably and uncontaminated by synthetic pesticides or genetically modified organisms [23], as well as for biodegradable packaging [15,17].

As it has previously been mentioned, phytotherapeutic products are used to prevent the development of diseases, improve health and well-being, or as an alternative if conventional medicine has been ineffective [16]. However, the perception of these remedies as safe and free of side effects is not completely true [24] as their safety and efficacy are sometimes questionable $[10,24,25]$ due to their complexity and variability [25-27]. Such concerns about herbal products refer to the exact dose, duration of treatment, side effects, acute and chronic toxicity and standardization [2].

Alongside their medical use, MAPs are frequently used in cosmetics and personal care products and can treat skin conditions such as dandruff or acne [28]. There is also a risk of side effects [29] when applied to the skin, mainly in the range of allergic reactions, such as contact dermatitis [30].

Assessing the quality of products obtained from MAPs is difficult due to their heterogeneity from the raw material itself, which may vary in chemical composition depending on environmental conditions (altitude, climate, time of harvest) and drying, storing and processing methods $[9,26,27]$. In order to ensure the safety and efficacy of these products, guidelines on good practices for the plant products quality assurance and protection in terms of contaminants, good agricultural practices, collection and processing have been developed [31]. Such practices may help to reduce the number of noncompliant (contaminated or adulterated) products on the market, which may pose a health hazard [23]. In addition, documenting all stages of production, thus ensuring product traceability, brings additional benefits to consumers [11]. One way to increase product safety is to use environmentally friendly raw materials [23]. Certification imposes certain standards on producers to ensure the quality of the final product, from raw material collection to product placement, with a role in the sustainable management of natural resources and biodiversity [32,33].

\section{Literature Review}

2.1. Consumption Characteristics for Products Obtained from Medicinal and Aromatic Plants Used for Phytotherapeutic Purposes

Preserving one's state of health would be the best predictor for the use of phytotherapeutic products and botanical supplements [34-36]. Consumers use these products as part of their family tradition, due to their preference for natural therapies, recommendations of specialists or personal research. Other considerations also emerge, such as distrust in allopathic medicine, inefficiency of allopathic therapy or confidence that natural therapies do not produce side effects [35]. 
From the sociodemographic point of view, there is flexibility in choosing products obtained from medicinal plants, especially for highly educated consumers aged 41-60 years [37,38]. Consumption increases with the level of education and income [34,38-40], with a higher consumption of medicinal herbs among women, who are more aware of certain health problems [39]. It can also be observed that the higher the consumption, the more significant the interest in a healthy lifestyle, giving up smoking and regular exercise [40].

The consumption of phytotherapeutic products is generally a matter of personal initiative or recommendation of a person without medical training, without prior consultation of a doctor or pharmacist, as is the case, for example, of consumers in Serbia [38], Turkey [34] and Lebanon [41]. On the other hand, for Czech consumers, specialist books, the media and family tradition are the main sources of information, with aspects of traditional medicine very well-documented in Czech literature [42].

The trust that consumers place in various specialists in the herbal sector is different. Thus, Brousse et al. [35] highlights low consumer confidence in pharmacists. On the other hand, pharmacists are an important source of information for consumers in the Czech Republic [42] and Madrid [43], where they are regarded as professionals in the field of medicinal plants [43].

There is high prevalence among consumers of not informing doctors or specialists in complementary medicine about the consumption of these products at their own will $[21,36,40,44,45]$. However, in the study by Harnack et al. [46], the vast majority of respondents agreed that it would be a good idea to consult a doctor before using a herbal product and that they should inform the doctor about the products used. Communication between the physician and the patient plays an important role in consumer practices and prevention of possible adverse reactions and interactions with allopathic treatments [44].

Moreover, how consumers evaluate the effectiveness of these products varies: some consider them to be effective or more effective than conventional medicines $[40,47]$ while others consider them to be less effective than conventional medicines but safer, exhibiting a lower risk of side effects, interactions with other medicines and addictions [44]. The results of numerous studies indicate the existence of misconceptions about the consumption safety for these products, such as the lack of side effects [21,34,38,41]. Nevertheless, other consumers acknowledge the possible toxicity of herbal products [46] as well as the main associated risks: wrong dosage and adverse/allergic reactions [35]. It is also women with higher incomes [34] and those over the age of 50 [48] who tend to be more aware of the possible side effects of these products.

\subsection{Consumption Characteristics of Medicinal and Aromatic Plant Products Used for Cosmetic and Personal Care Purposes}

Nowadays, the demand for organic and natural cosmetics is constantly growing, and this category also includes cosmetics with MAP ingredients [49]. As such, protecting the environment and animals, ensuring health and safety have proven to be important factors influencing the consumption of these products [50,51].

From the sociodemographic point of view, women are more likely to buy natural cosmetics [18] as they are concerned with sustainability and health issues and exhibit a positive attitude towards the consumption of ecological and personal care cosmetics [50]. However, a study by Cervellon and Carey [52] found that consumers do not understand the meaning of all terms and labels used to describe and guarantee organic products, and the reasons for using organic cosmetics are self-centred and health-related, while environmental protection is not a priority [52]. This observation is contrary to other research showing a positive attitude towards the environment influencing the higher tendency to buy natural cosmetics $[53,54]$.

Consumers generally choose organic personal care products because they perceive them to contain ingredients from the nature and, therefore, to be safe, while their perceived quality does not significantly influence the tendency to choose such products [55].

The existing studies, however, show that the lack of regulations, misleading marketing information and the multitude of terms used to describe natural cosmetics (organic, natural, 
herbal, eco-friendly) reduce confidence in these products and cause confusion among consumers, thus favouring a negative attitude towards their consumption $[14,15,52]$.

\subsection{Consumer Clusters and Medicinal and Aromatic Plant Products Preferences}

In recent years, a special attention for cluster analysis can be noticed as it is an important and universal tool with multiple applications [56-58].

There are few literature studies on the clustering of consumers of products obtained from MAPs. For instance, Güney [59] segmented consumers in Turkey according to their knowledge and perceptions of MAPs, obtaining three distinct consumer groups: the first includes people who are reluctant to consume these products as they show concern about possible side effects and who consider the price of MAP products high; the second is made up of people who want to consume these products, buy them mainly from supermarkets and give high importance to the brand; and the third includes people who prefer natural products while being aware of environmental protection and healthcare [59].

Sharifi et al. [60] also conducted segmentation of herbal medicine consumers in Iran based on the following factors: healthcare, distribution, product characteristics, price, purchase intention, attitude, publicity and lifestyle, ultimately clustering consumers into four distinct segments: Segment 1-people with a positive attitude interested in their state of health who have been assigned a high share of all factors, except for the characteristics of the product; Segment 2-people with a negative attitude reluctant towards their health who were assigned a small share of all factors; Segment 3-lifestyle-oriented potential consumers who were assigned a moderate share of several categories, except for lifestyle; Segment 4-price-oriented potential consumers who were assigned a moderate share for several categories, with the exception of purchase intention and advertising [60].

Additionally, in a study conducted in Hungary, the health-related attitudes of those who use medicinal plants were analysed taking into account the following factors: health awareness, sports, healthy nutrition, medical check-ups. This resulted in five consumer segments: cluster 1, "comprehensive regenerators", use medicinal plants the least; cluster 2, "seeking objective control", use medicinal plants most frequently and are aware of health and the environment; cluster 3, "comprehensive health consciousness", retained consumers of medicinal plants, the most interested in health and the environment; cluster 4 , "regenerating with food", use medicinal plants less frequently than cluster 2 and are more environmentally conscious than the health-conscious; "non-users" [39].

Clustering of natural cosmetics consumers was achieved by Amberg and Fogarassy [17], where the variables analysed were as follows: openness to new brands of cosmetics, health awareness, avoidance of organic food, environmental awareness, natural ingredients, natural packaging and preference for natural cosmetics to the detriment of chemical ones despite their lower efficiency. The results yielded three clusters: "Natural" prefer new brands, are health- and environmentally conscious, prefer natural ingredients and packaging; "Non-natural" — avoid the purchase of organic food and prefer chemical cosmetics instead of natural ones; "Mixed" - avoid organic food and natural cosmetics to a lesser extent [17].

Truong [61] identified clusters of consumers of green cosmetics in Finland based on three variables: purchase intention, attitude and concern for the environment. The statistical analysis resulted in three distinct segments, namely "the indifferent" — do not exhibit environmental protection behaviour and are unlikely to buy products manufactured or packaged in recycled or environmentally certified materials; "the active green" - use biodegradable, recyclable or environmentally certified products, are more tolerant of the limited effectiveness of environmentally friendly alternatives, slightly sceptical about the environmental claims of traders and inquire about a green cosmetic product before buying; "the inactive green"-are willing to pay extra for a green cosmetic product only if it is as effective as the conventional one, extremely judicious about green marketing messages, questioning the authenticity of the information [61]. 
Similarly, Eberhart et al. [62] identified three consumer segments in relation to how they perceive sustainability issues in the context of personal care products: "unreflecting consumers" are generally unaware of sustainability issues and do not link sustainability and personal care products, are not aware of the social or environmental consequences of their behaviour; "limited consumers" are aware of sustainability aspects that they correlate with environmental protection and conservation; however, they do not take action in this respect; "responsible consumers" are aware of all the three components of sustainable behaviour (economic, social and environmental), able to identify and purchase sustainable products [62].

Data on the consumption behaviour for products obtained from medicinal and aromatic plants for the Romanian population are limited. Therefore, the main purpose of this study was to identify the factors that influence the purchase of medicinal and aromatic plant products for phytotherapeutic, cosmetic and personal care purposes by the population of Cluj-Napoca. The novelty of the research was based on the cluster analysis approach that allowed segmenting consumers according to their perceptions, attitudes and consumption habits. The investigation focused on consumer interest for sustainable behaviour related to the consumption of products obtained from medicinal and aromatic plants.

\section{Materials and Methods}

\subsection{Questionnaire Structure}

In order to design the questionnaire, a literature study was performed alongside other research on the consumption behaviour for products obtained from MAPs $[18,34,35,59,63,64]$.

As such, the questionnaire included the first question where participants agreed with the application of the General Data Protection Regulation (GDPR), followed by two filter questions with a selection purpose, as the study was only aimed at permanent residents of Cluj-Napoca and consumers of products obtained from medicinal and aromatic plants. In addition, the questionnaire presented two more filter questions aimed at separating consumers according to the purpose of use, phytotherapeutic ("Question 12. Do you use medicinal and aromatic plant products to prevent and/or treat certain diseases?") or cosmetic ("Question 27. Do you use medicinal and aromatic plant products for cosmetic and personal care purposes?"). The questionnaire included questions on the attitudes, perceptions and consumption practices regarding MAP products used to prevent and/or treat certain ailments, including cosmetic and personal care use. It concluded with some general aspects related to health, lifestyle, sustainability and sociodemographic data. The questions were all Likert-scale, single- or multiple-choice. All the items included in the analysis are presented in the supplementary file.

\subsection{Data Collection}

The target population was represented by people from Cluj-Napoca who consumed medicinal and aromatic plant products for phytotherapeutic and/or cosmetic and personal care purposes, and the sampling method chosen was the ad-hoc method (convenience sampling).

Data collection was carried out between June and September 2020 in two ways: "faceto-face" and online. The pandemic context caused by COVID-19 limited the collection of "face-to-face" data, so it was performed mostly online as the questionnaire was distributed using social media according to the snowball method. The participation was voluntary and anonymous, the participants were informed about the purpose of the research and about the protection of personal data from the beginning.

Data collection resulted in 620 valid responses. The two filter questions allowed the identification of two user groups for medicinal and aromatic plant products from the total sample: the first group consisting of 231 respondents using medicinal and aromatic plant products for phytotherapeutic purposes and the second group consisting of 297 respondents who used these products for cosmetic and personal care purposes. 


\subsection{Statistical Analysis}

Descriptive statistics were used to summarize the data for the entire sample and for each group of respondents identified based on the filter questions that determined the users of medicinal and aromatic plants for the two main purposes: phytotherapeutic use or cosmetic use. Subsequently, the $k$-means clustering analysis was employed to identify groups of consumers of distinct patterns based on the purpose and frequency of their use and on the sociodemographic features. The non-hierarchical clustering analysis is widely used for large samples [65]. It helps classify respondents into different groups by assigning data into clusters that are closer to the centres [66]. The variables were standardized to avoid any effects caused by unequal scaling that could affect the clustering results [65] and eliminated from the construction of clusters if the $p$-value was less than 0.05 . The number of clusters was increased or decreased sequentially until the cluster centres stabilized [67]. During the analysis, the reallocation of subjects to clusters occurred until the maximum number of iterations was achieved [68]. The differences between the clusters were identified using one-way ANOVA tests with the $p$-value of 0.05 considered to be statistically significant. The data were analysed using statistical package SPSS 24.0.

\section{Results}

\subsection{Sociodemographics Characteristics of the Sample}

Table 1 presents the sociodemographic characteristics of the two distinct groups of consumers: group 1 represented by those who use them for phytotherapeutic purposes and group 2 represented by those who use them for cosmetic and personal care purposes.

The group including consumers of MAP products for phytotherapeutic purposes consisted of 231 respondents, $67.1 \%$ women and $32.9 \%$ men, with more than $60 \%$ aged between 25 and 44 years. There was a higher preponderance of graduates of university $(45.5 \%)$ and post-university studies (32.5\%), as well as those with incomes of 2001-3000 RON (23.4\%) and 3001-4000 RON (19.9\%). Their main occupation category was that of an employee $(65.8 \%)$ followed by a freelancer $(16.9 \%)$.

Conversely, the second group included 297 respondents who used MAP products for cosmetic and personal care purposes, of which $75.1 \%$ were women and $24.9 \%$ were men, with $60 \%$ aged between 25 and 44 years. Those with university studies $(45.1 \%)$ were predominant, followed by those with post-university $(25.3 \%)$ and high school studies $(21.2 \%)$. Furthermore, within this group, the main occupation category was that of an employee (69.4\%), while in terms of income, $24.9 \%$ reported incomes of 2001-3000 RON, $23.2 \%$ of 3001-4000 RON.

Table 1. Sample characteristics.

\begin{tabular}{|c|c|c|c|c|c|}
\hline \multirow{2}{*}{$\begin{array}{l}\text { Sociodemographic } \\
\text { Characteristics }\end{array}$} & \multirow{2}{*}{ Variable } & \multicolumn{2}{|c|}{$\begin{array}{c}\text { Group 1-Phytotherapeutic } \\
\text { Purposes }(N=231)\end{array}$} & \multicolumn{2}{|c|}{$\begin{array}{c}\text { Group 2-Cosmetic and Personal } \\
\text { Care Purposes }(N=297)\end{array}$} \\
\hline & & No. & $\%$ & No. & $\%$ \\
\hline \multirow{2}{*}{ Gender } & Male & 76 & 32.9 & 74 & 24.9 \\
\hline & Female & 155 & 67.1 & 223 & 75.1 \\
\hline \multirow{5}{*}{ Age } & $<25$ years & 19 & 8.2 & 39 & 13.1 \\
\hline & 25-34 years & 66 & 28.6 & 93 & 31.3 \\
\hline & 35-44 years & 80 & 34.6 & 85 & 28.6 \\
\hline & $45-54$ years & 37 & 16.0 & 59 & 19.9 \\
\hline & $>55$ years & 29 & 12.6 & 21 & 7.1 \\
\hline
\end{tabular}


Table 1. Cont.

\begin{tabular}{|c|c|c|c|c|c|}
\hline \multirow{2}{*}{$\begin{array}{l}\text { Sociodemographic } \\
\text { Characteristics }\end{array}$} & \multirow{2}{*}{ Variable } & \multicolumn{2}{|c|}{$\begin{array}{l}\text { Group 1-Phytotherapeutic } \\
\text { Purposes }(N=231)\end{array}$} & \multicolumn{2}{|c|}{$\begin{array}{c}\text { Group 2-Cosmetic and Personal } \\
\text { Care Purposes }(N=297)\end{array}$} \\
\hline & & No. & $\%$ & No. & $\%$ \\
\hline \multirow{6}{*}{ Education } & No education & 4 & 1.7 & - & - \\
\hline & Professional, vocational school & 6 & 2.6 & 15 & 5.0 \\
\hline & High school & 26 & 11.2 & 63 & 21.2 \\
\hline & Post-secondary school for masters & 15 & 6.5 & 10 & 3.4 \\
\hline & Graduate studies & 105 & 45.5 & 134 & 45.1 \\
\hline & Postgraduate studies & 75 & 32.5 & 75 & 25.3 \\
\hline \multirow{5}{*}{ Main occupation } & Student & 12 & 5.2 & 28 & 9.4 \\
\hline & Houseperson, unemployed & 9 & 3.9 & 10 & 3.4 \\
\hline & Retired, unable to work & 19 & 8.2 & 11 & 3.7 \\
\hline & Employed & 152 & 65.8 & 206 & 69.4 \\
\hline & Self-employed, freelancer & 39 & 16.9 & 42 & 14.1 \\
\hline \multirow{8}{*}{ Income $\left(\mathrm{RON}^{*}\right)$} & No income & 6 & 2.6 & 9 & 3 \\
\hline & Maximum $1000 \mathrm{RON}$ & 5 & 2.2 & 7 & 2.4 \\
\hline & 1001-2000 RON & 34 & 14.7 & 46 & 15.5 \\
\hline & 2001-3000 RON & 54 & 23.4 & 74 & 24.9 \\
\hline & 3001-4000 RON & 46 & 19.9 & 69 & 23.2 \\
\hline & 4001-5000 RON & 33 & 14.3 & 40 & 13.5 \\
\hline & 5001-6000 RON & 18 & 7.8 & 22 & 7.4 \\
\hline & $>6000 \mathrm{RON}$ & 35 & 15.1 & 30 & 10.1 \\
\hline
\end{tabular}

* Exchange rate (the average value for 2020): $1 \mathrm{EUR}=4.8371 \mathrm{RON}$ (Romanian Leu).

\subsection{Clusters of Consumers Using Medicinal and Aromatic Plant Products for Phytotherapeutic Purposes}

With respect to consumers who used MAP products for phytotherapeutic purposes, two clusters of consumers, the "Curious" and the "Knowledgeable", were identified (Figure 1). The final clusters yielded results after four iterations. The variables that were not significant were eliminated based on the ANOVA test [69]. As such, the first cluster consisted of 46 consumers, the second-of 95 consumers.

Figure 1 presents the final clusters according to the standardized scores, while the variables were grouped into three categories: (1) health issues leading to the use of MAP products; (2) the reasons for these products to be used for phytotherapeutic purposes and consumption-influencing factors; (3) the sources of information used and the trust placed in these sources. The questions that generated statistically significant correlations and were included in the cluster analysis are presented in Table S1. One-way ANOVA tests indicated that sociodemographic variables do not contribute to the construction of clusters, therefore they were excluded from the final clusters. 


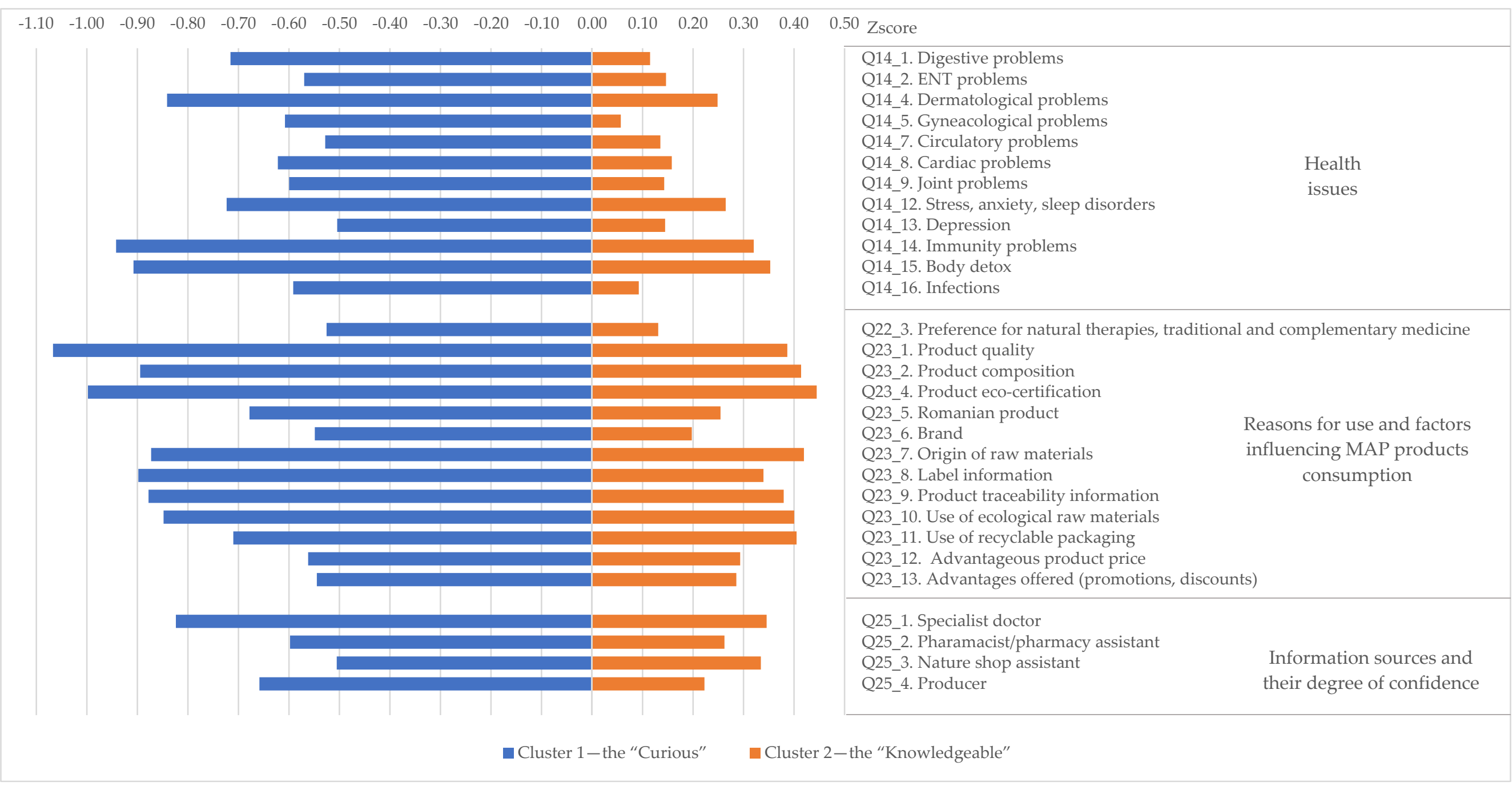

Figure 1. Clustering results—use of medicinal and aromatic plant products for phytotherapeutic purposes. 
Figure 1 reveals details about the profile of each cluster extracted in the case of consumers that use MAP products for phytotherapeutic purposes. Cluster 1, the "Curious", were those who occasionally used MAP products to prevent and/or treat a number of conditions. Their use predominantly depended on their need as they revealed a lower preference for natural therapies as well as traditional and complementary medicine. Regarding the reasons for choosing MAP products for therapeutic purposes, two characteristics were slightly more relevant: high dependence of the purchase highly on promotions or discounts or advantageous purchase price. When it comes to their information sources for the use of herbal remedies, only the staff of health food stores or pharmacists were more often invested with confidence, but with very little differentiation compared to other sources.

Cluster 2, the "Knowledgeable", included those who used MAP products to prevent and / or treat a wide range of ailments. It can be stated that this practice was used for any kind of condition. Such favourable responses for all the surveyed items suggested a positive attitude towards these products. The consumption habit seemed to be one of prevention, due to the wide range of uses. They were more interested in the products being quality ecologically certified products rather than in price offers. They also revealed knowledge about the composition of the preparations and product traceability. Like sommeliers, it is pertinent to say they were knowledgeable in the field, differing in their emphasis on the origin of the raw materials. They got their information from a specialist doctor or as a result of the direct relationship they had with the producer.

\subsection{Clusters of Consumers Using Medicinal and Aromatic Plant Products for Cosmetic and Personal Care Purposes}

Similarly, in the case of those who used MAP products for cosmetic and personal care purposes, two clusters of consumers called the "Curious" and the "Knowledgeable" were identified. The final clusters yielded results after seven iterations. The variables that were not significant were eliminated based on the ANOVA test [69]. The first cluster consisted of 62 consumers, the second-of 177 consumers.

Figure 2 presents the final clusters according to the standardized scores, the variables being grouped into three categories: (1) the reasons that determined the use and the factors that influenced the consumption of MAP products for cosmetic and personal care purposes; (2) the sources of information used as well as the trust placed in them; (3) interest in environmental sustainability. The questions that generated statistically significant correlations and were included in the cluster analysis are presented in Table S2. Furthermore, the one-way ANOVA tests indicated that sociodemographic variables did not contribute to the construction of clusters; therefore, they were excluded from the final clusters.

Figure 2 reveals details about the profile of each cluster extracted in the case of consumers using MAP products for cosmetic and personal purposes. Cluster 1, the "Curious", seemed to be those who tried medicinal and aromatic products for cosmetic and personal care purposes or who used them for more limited purposes than others. They were not as interested in the specific elements of the products and chose the products more often depending on the smell, scientifically proven benefits, appearance and preferred them to be Romanian products. They stated that their information was a little more often sourced from specialized books than other sources. On this topic, they trusted pharmacists, specialized staff from stores and books. They were less willing to pay more for cosmetics and personal care products with 100\% natural ingredients from medicinal and aromatic plants. 


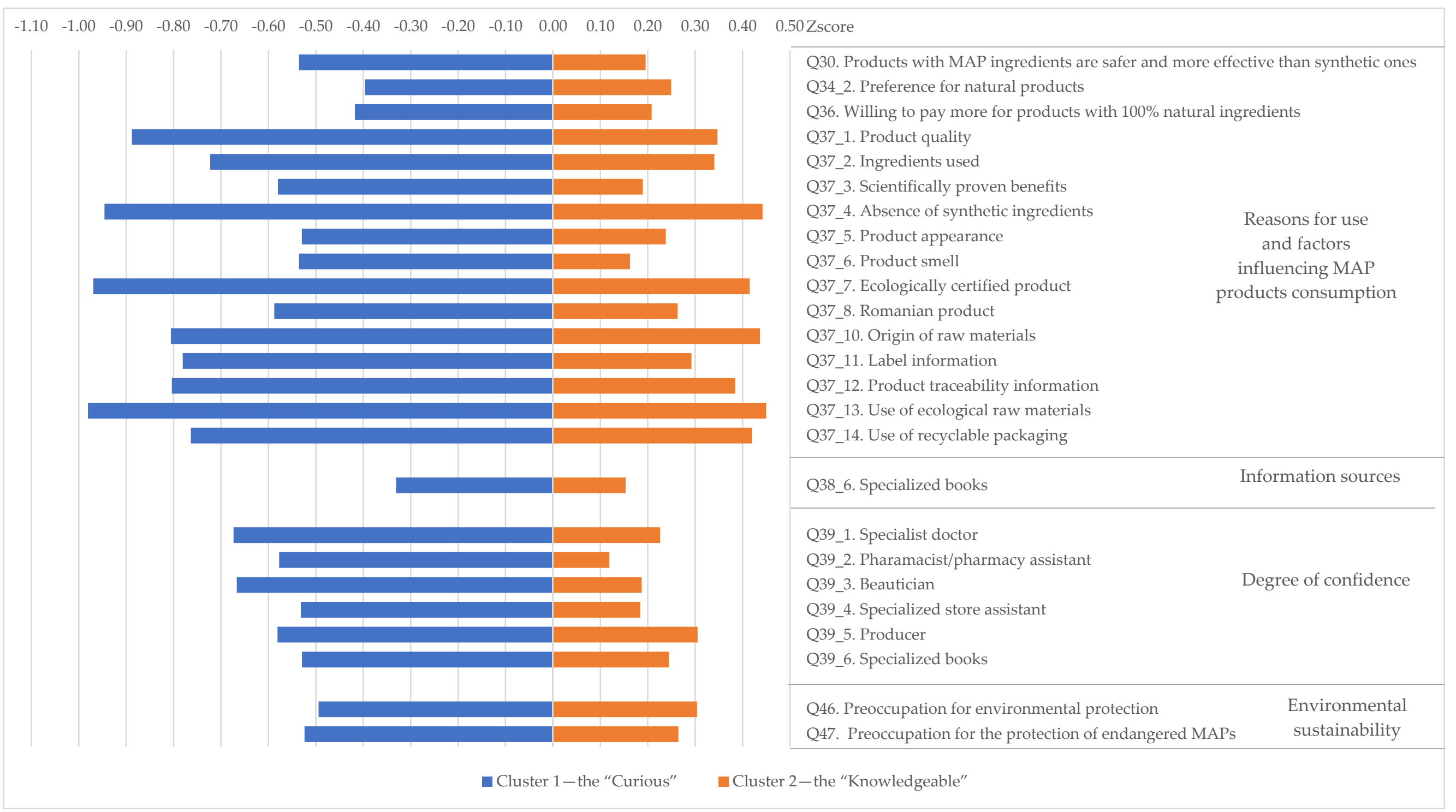

Figure 2. Clustering results—use of medicinal and aromatic plant products for cosmetic and personal care purposes. 
Cluster 2, the "Knowledgeable", included those who generally preferred cosmetic and personal care products from MAP as they considered them to be safer and more effective. In making their choice, it can be observed that they were quite selective in relying on a wide range of criteria. They were highly concerned with the raw materials used, their origin and quality and that products did not contain synthetic ingredients and were organically certified. When choosing or deciding to use cosmetics and personal care products with medicinal and aromatic plant ingredients, they differed from others in that they placed their greatest confidence in producers and specialist doctors. They considered themselves to be concerned with the protection of the environment and endangered medicinal and aromatic plant species. They were willing to pay more for cosmetics and personal care products with $100 \%$ natural medicinal and aromatic plant ingredients.

\section{Discussion}

As such, the main purpose of this research was to identify clusters of consumers that use MAP products for phytotherapeutic and cosmetic purposes in Cluj-Napoca according to the consumption-influencing reasons and factors as well as information sources and trust placed in them. An important aim of the study was to identify the existence of a possible correlation between the consumption of MAP products and the interest in healthy lifestyle and sustainable behaviour. The results revealed the existence of two clusters of consumers, both in the group who used them for phytotherapeutic purposes and those who used them for cosmetic and personal care purposes: the "Curious" and the "Knowledgeable".

From the sociodemographic point of view, in the two distinct groups of consumersthose who use MAP products for phytotherapeutic purposes and those who use them for cosmetic and personal care purposes - there was a higher percentage of consumers with university and postgraduate studies and higher income. According to other research in the field, product consumption increases with the level of education and income [34,38-40]. In addition, there was a greater interest among women for these product categories, which is similar to other studies [18,39].

In terms of MAP products use for phytotherapeutic purposes, the "Knowledgeable" cluster motivated their use by their preference for natural therapies. This practice is associated with their safety and efficacy perception as they are natural and due to longterm use over time [10,21]. In the research conducted by Polereczki et al. [39] among Hungarian consumers, health awareness is the factor that most influences purchasing decisions. However, in this case, the medical recommendation is present in very few cases. In the present research, both among the "Knowledgeable" and the "Curious", the trust placed in specialists was observed. Thus, when the "Knowledgeable" wanted to find out about the choice or use of MAP products for phytotherapeutic purposes, they turned to a specialist or the producer. At the same time, among the "Curious", there was some trust placed in pharmacists and staff at specialty stores. These attitudes are beneficial for they can prevent adverse reactions or their improper use, compared to the results of other studies where consumers rely on information from friends, relatives, the media and do not communicate their consumption practices to doctors or pharmacists $[34,38,41]$.

On the other hand, the "Curious" group exhibited no preference for natural therapies, traditional and complementary medicine as they used medicinal and aromatic herbal products for phytotherapeutic purposes only when in need. A possible hypothesis for future research would focus on whether this use in need occurs before conventional medications or because the latter has not proven effective.

As for the "Knowledgeable" who use these products for their phytotherapeutic purposes, there was an increased interest in the issues related to environmental protection and health. They generally used herbal products to prevent and/or treat a wide range of health problems, which shows that they were concerned about their health, paying attention to the ecological certification, quality, composition and traceability of products. The "Knowledgeable" can be likened to "seeking objective check-ups" in the research of Polereczki et al. [39], with both groups using herbal products for a wide range of ailments, 
such as immunity problems, stress, anxiety, sleep disorders, dermatological problems, etc., according to our results. We can assume that they had a preventive health behaviour, also confirmed by the fact that "seeking objective check-ups" continuously check their health state through regular medical check-ups. In addition, for those "seeking objective check-ups", the factors influencing their consumption decisions are also in favour of protecting the environment [39]. The same can be said about the "Knowledgeable", as their environmental protection interest resided in the use of ecologically certified products.

Consumers of the "Knowledgeable" cluster in the group of MAP product users for cosmetic and personal care purposes stated that they were concerned about sustainability issues, which is also highlighted by their behaviour: they used ecological products and were interested in protecting endangered species. This group was health-conscious, paying attention to the ingredients in the cosmetic and personal care products they purchased and the possible effects they could have on the skin. Thus, when buying products, they focused on the raw materials used, their origin and quality and made sure that the products did not contain synthetic ingredients and were organically certified. This finding is consistent with previous studies $[17,61,62]$ that identified similar patterns of behaviour following cluster analysis. They have similar characteristics to cluster 1 "Natural" in Amberg and Fogarassy's research, with a preference for new brands, natural ingredients and recyclable packaging, care for environmental protection and health [17]; to the "the active green" cluster in Truong's research, made up of consumers who are inclined to use environmentally friendly, biodegradable, recyclable or environmentally certified ingredients [61]; and to the "responsible consumers" cluster in Eberhart and Naderer's research, made up of consumers who are aware of sustainability issues and able to identify and purchase sustainable personal care products [62]. In addition, the "Knowledgeable" were willing to buy natural cosmetics with $100 \%$ natural ingredients, even if they were more expensive than synthetic ones.

Contrary to this consumption behaviour, the consumers of the "green active" cluster do not seem willing to pay extra, but are more tolerant of the limited effectiveness of green alternatives [61]. When it comes to the ingredients used, it seems that those in the "Curious" group were less willing to pay extra for $100 \%$ natural ingredients, choosing products based on smell, scientifically proven benefits or appearance.

An important aspect sought by frequent consumers of such products both for phytotherapeutic and cosmetic purposes and personal care is the quality of the product. Assessing the quality of products obtained from medicinal and aromatic plants is difficult due to their complexity, but the use of organic raw materials as well as traceability information are a way to ensure quality and safety of these products [11,23]. In Romania, although there are European regulations on the quality conditions of these products, there is a lack of product monitoring [70]. Product quality is an objective factor, but the way in which it is assessed by the consumer is a subjective factor [49]. Based on the results obtained, it is considered that consumer information and education campaigns in this direction may be needed, as well as academic/training programmes of specialists involved in public health (doctors, pharmacists) so as to ensure the correct and safe use by consumers. The involvement of policymakers through the development of policies and regulations regarding the monitoring of products sold in the market would also be beneficial.

\section{Conclusions}

There are various preferences when it comes to consuming MAP products for phytotherapeutic or cosmetic purposes as confirmed by this study and by other similar research [17,39,59-62]. The abovementioned results show that consumers within each resulting cluster have common characteristics in the attitudes and factors that influence their consumption practices. For the "Knowledgeable", the reason for choosing MAP products resides in their preference for natural therapies, traditional and complementary medicine while placing a lot of trust in specialists when they seek information on MAP products. As for phytotherapeutic use, for consumers in the second cluster, the consumption habit seems 
to be one of prevention as they use MAP products for a wide range of health problems. On the other hand, the first cluster uses them only when in need. An important aspect observed was that for the "Knowledgeable", the health and environmental protection concerns positively influence the consumption of these products as they are heavy users of ecologically certified MAP products.

From the management point of view, the results obtained can be beneficial to stakeholders in the pharmaceutical and cosmetics industry by developing and innovating new products based on consumer needs and desires. To this end, it would be appropriate for producers and processors to profess the concepts of sustainability, including the development of environmentally certified products in accordance with the European Green Deal which aims to stimulate efficient use of resources by moving to a circular economy and reduce pollution [71]. As organic farming is currently developing in Romania, it could be assumed that the use of certified organic medicinal and aromatic plants as raw materials could lead to significant economic benefits and further development of this industrial sector. Furthermore, it is believed that the organization of marketing strategies to promote these issues would be an important factor in encouraging sustainable consumption behaviour.

However, the limitation of this research consists in the chosen sampling method, the convenience sampling method being non-probabilistic; therefore, it does not allow for the generalization of the results obtained. Future work should address the integration of consumers from other countries to identify the possible differences in MAP products consumption patterns. Another research direction would be to investigate whether the inclusion of consumers into reference groups influences their purchase behaviour considering that social networks play a decisive role in daily life [56].

Supplementary Materials: The following are available online at https:/ / www.mdpi.com/article/10 $.3390 /$ su13158648/s1, Table S1: Questionnaire items used in the cluster analysis for phytotherapeutic purposes, Table S2: Questionnaire items used in the cluster analysis for cosmetic and personal care purposes.

Author Contributions: Conceptualization, R.-L.C. and C.B.P.; methodology, R.-L.C. and C.B.P.; software, A.A.; validation, C.B.P. and D.E.D.; formal analysis, R.-L.C. and A.A.; investigation, R.-L.C.; resources, R.-L.C.; data curation, R.-L.C., A.A. and D.E.D.; writing-original draft preparation, R.-L.C. and C.B.P.; writing-review and editing, C.B.P., D.E.D. and M.M.; visualization, R.-L.C. and C.B.P.; supervision, C.B.P. All authors have read and agreed to the published version of the manuscript.

Funding: This research received no external funding.

Data Availability Statement: Not applicable.

Conflicts of Interest: The author Roxana-Larisa Cadar is an employee of MDPI; however, she did not work for the journal Sustainability at the time of submission and publication.

\section{References}

1. Inoue, M.; Hayashi, S.; Craker, L.E. Culture, History and Applications of Medicinal and Aromatic Plants in Japan. In Aromatic and Medicinal Plants-Back to Nature; InTech: Rijeka, Croatia, 2017. [CrossRef]

2. Jamshidi-Kia, F.; Lorigooini, Z.; Amini-Khoei, H. Medicinal Plants: Past History and Future Perspective. J. HerbMed Pharmacol. 2018, 7, 1-7. [CrossRef]

3. Chaudhri, S.K.; Jain, N.K. History of Cosmetics. Asian J. Pharm. 2014, 3, 164-167. [CrossRef]

4. Sytar, O.; Brestic, M.; Hajihashemi, S.; Skalicky, M.; Kubeš, J.; Lamilla-Tamayo, L.; Ibrahimova, U.; Ibadullayeva, S.; Landi, M. COVID-19 Prophylaxis Efforts Based on Natural Antiviral Plant Extracts and Their Compounds. Molecules 2021, $26,727$. [CrossRef]

5. Agostini, C.T.S.; Vieira, R.F.; Bizzo, H.R.; Silveira, D.; Gimenes, M.A. Secondary Metabolites. In Chromatography and Its Applications; InTech: Rijeka, Croatia, 2012. [CrossRef]

6. Neffati, M.; Sghaier, M. Developpement et Valorisation des Plantes Aromatiques et Medicinales (PAM) au Niveau des Zones Desertiques de la Région MENA (Algérie, Egypte, Jordanie, Maroc et Tunisie); Observatoire du Sahara et du Sahel: Tunis, Tunisia, 2014.

7. Dhifi, W.; Bellili, S.; Jazi, S.; Bahloul, N.; Mnif, W. Essential Oils' Chemical Characterization and Investigation of Some Biological Activities: A Critical Review. Medicines 2016, 3, 25. [CrossRef] [PubMed] 
8. Kabera, J.; Semana, E.; Mussa, A.R.; He, X. Plant Secondary Metabolites: Biosynthesis, Classification, Function and Pharmacological Classification, Function and Pharmacological Properties Ethnobotanical Survey of Medicinal Plants with Pesticides Properties and Their Potential Use in Rwanda View Pro. J. Pharm. Pharmacol. 2014, 2, 377-392.

9. Shipkowski, K.A.; Betz, J.M.; Birnbaum, L.S.; Bucher, J.R.; Coates, P.M.; Hopp, D.C.; MacKay, D.; Oketch-Rabah, H.; Walker, N.J.; Welch, C.; et al. Naturally Complex: Perspectives and Challenges Associated with Botanical Dietary Supplement Safety Assessment. Food Chem. Toxicol. 2018, 118, 963-971. [CrossRef] [PubMed]

10. Cassileth, B.R.; Heitzer, M.; Wesa, K. The Public Health Impact of Herbs and Nutritional Supplements. Pharm. Biol. 2009, 47, 761-767. [CrossRef]

11. Lubbe, A.; Verpoorte, R. Cultivation of Medicinal and Aromatic Plants for Specialty Industrial Materials. Ind. Crops Prod. 2011, 34, 785-801. [CrossRef]

12. Labbé, J. Les Plantes Médicinales et L'herboristerie: À La Croisée de Savoirs Ancestraux et D'enjeux D'avenir.; Rapport D'information, Fait au Nom de la MI Développement de L’herboristerie; Sénat: Paris, France, 2018.

13. Enioutina, E.Y.; Job, K.M.; Krepkova, L.V.; Reed, M.D.; Sherwin, C.M. How Can We Improve the Safe Use of Herbal Medicine and Other Natural Products? A Clinical Pharmacologist Mission. Expert Rev. Clin. Pharmacol. 2020, 13, 935-944. [CrossRef]

14. Zhang, J.; Zhou, M. Factors Influencing Consumer Purchasing Behavior of Natural Cosmetics-A Qualitative Study in Uppsala, Sweden. Master's Thesis, Uppsala University, Uppsala, Sweden, 2019.

15. Lin, Y.; Yang, S.; Hanifah, H.; Iqbal, Q. An Exploratory Study of Consumer Attitudes toward Green Cosmetics in the UK Market. Adm. Sci. 2018, 8, 71. [CrossRef]

16. Enioutina, E.Y.; Salis, E.R.; Job, K.M.; Gubarev, M.I.; Krepkova, L.V.; Sherwin, C.M.T. Herbal Medicines: Challenges in the Modern World. Part 5. Status and Current Directions of Complementary and Alternative Herbal Medicine Worldwide. Expert Rev. Clin. Pharmacol. 2017, 10, 327-338. [CrossRef]

17. Amberg, N.; Fogarassy, C. Green Consumer Behavior in the Cosmetics Market. Resources 2019, 8, 137. [CrossRef]

18. Matić, M.; Puh, B. Consumers' Purchase Intentions towards Natural Cosmetics. Ekon. Vjesn. Econviews Rev. Contemp. Bus. Entrep. Econ. Issues 2016, 29, 53-64.

19. Katsikis, I.N. Market Demand, Eco-Products and Entrepreneurship in the "natural Cosmetics Sector" in Greece. In Entrepreneurship, Innovation and Sustainability; Routledge: London, UK, 2019; pp. 238-251. [CrossRef]

20. Mordeniz, C. Introductory Chapter: Traditional and Complementary Medicine. Tradit. Complement. Med. 2019. [CrossRef]

21. Giveon, S.M.; Liberman, N.; Klang, S.; Kahan, E. Are People Who Use "Natural Drugs" Aware of Their Potentially Harmful Side Effects and Reporting to Family Physician? Patient Educ. Couns. 2004, 53, 5-11. [CrossRef]

22. WHO Global Report on Traditional and Complementary Medicine 2019; WHO: Geneva, Switzerland, 2019.

23. Craker, L.E. Medicinal and Aromatic Plants-Future Opportunities. In Issues in New Crops and New Uses; ASHS Press: Alexandria, VA, USA, 2007; pp. 248-257.

24. Ekor, M. The Growing Use of Herbal Medicines: Issues Relating to Adverse Reactions and Challenges in Monitoring Safety. Front. Neurol. 2014, 4, 177. [CrossRef]

25. Carmona, F.; Soares Pereira, A.M. Herbal Medicines: Old and New Concepts, Truths and Misunderstandings. Rev. Bras. Farmacogn. 2013, 23, 379-385. [CrossRef]

26. Grigore, A.; Pirvu, L.; Bubueanu, C.; Colceru-Mihul, S.; Ionita, C.; Ionita, L. Medicinal Plant Crops-Important Source of High Value-Added Products. Sci. Papers Ser. A Agron. 2016, LIX, 298-307.

27. Shukla, S.S.; Saraf, S.; Saraf, A.S. Approaches towards Standardization and Quality Assessment of Herbals. J. Res. Educ. Indian Med. 2009, 1, 25-32.

28. Aburjai, T.; Natsheh, F.M. Plants Used in Cosmetics. Phytother. Res. 2003, 987-1000. [CrossRef]

29. Ribeiro, A.; Estanqueiro, M.; Oliveira, M.; Sousa Lobo, J. Main Benefits and Applicability of Plant Extracts in Skin Care Products. Cosmetics 2015, 2, 48-65. [CrossRef]

30. Jack, A.R.; Norris, P.L.; Storrs, F.J. Allergic Contact Dermatitis to Plant Extracts in Cosmetics. Semin. Cutan. Med. Surg. 2013, 32, 140-146. [CrossRef]

31. World Health Organization. WHO Guidelines for Assessing Quality of Herbal Medicines with Reference to Contaminants and Residues; WHO: Geneva, Switzerland, 2007.

32. Fonseca-Santos, B.; Antonio Corrêa, M.; Chorilli, M. Sustainability, Natural and Organic Cosmetics: Consumer, Products, Efficacy, Toxicological and Regulatory Considerations. Braz. J. Pharm. Sci. 2015, 51, 17-26. [CrossRef]

33. Jadranka, R. Incredible I Control and Certification of Ecological Medicinal and Aromatic Plants in Croatia I Incredible. Available online: https: / repository.incredibleforest.net/oppla-factsheet/20543 (accessed on 21 February 2021).

34. Korkmaz, M.; Fakir, H.; Guller, B. Consumer Preferences for Medicinal and Aromatic Plant Products: Surveys of Urban Consumers and Sellers in Western Mediterranean Region of Turkey. J. Med. Plants Res. 2011, 5, 2054-2063.

35. Brousse, C.; Gallé, J.-B. Analyse Des Résultats de L'enquête Consommateurs Mise en Ligne par la Fédération des Paysan.e.s-Herboristes; Rapport Finale; France AgriMer: Paris, France, 2017.

36. Marinac, J.S.; Buchinger, C.L.; Godfrey, L.A.; Wooten, J.M.; Sun, C.; Willsie, S.K. Herbal Products and Dietary Supplements: A Survey of Use, Attitudes, and Knowledge among Older Adults. J. Am. Osteopath. Assoc. 2007, 107, 13-23. [CrossRef]

37. Stoia, M.; Oancea, S. Herbal Dietary Supplements Consumption in Romania from the Perspective of Public Health and Education. Acta Med. Transilv. 2013, 2, 216-219. 
38. Samojlik, I.; Mijatović, V.; Gavarić, N.; Krstin, S.; Božin, B. Consumers' Attitude towards the Use and Safety of Herbal Medicines and Herbal Dietary Supplements in Serbia. Int. J. Clin. Pharm. 2013, 35, 835-840. [CrossRef] [PubMed]

39. Polereczki, Z.; Barna, F.; Prokisch, L.; Kovács, S.; Kontor, E.; Szakály, Z. The Characteristics of the Consumption of Medicinal Herbs in Hungary. J. Food Investig. 2019, 65, 2636-2645.

40. Kennedy, J. Herb and Supplement Use in the US Adult Population. Clin. Ther. 2005, 27, 1847-1858. [CrossRef]

41. El Khoury, G.; Ramadan, W.; Zeeni, N. Herbal Products and Dietary Supplements: A Cross-Sectional Survey of Use, Attitudes, and Knowledge Among the Lebanese Population. J. Community Health 2016, 41, 566-573. [CrossRef] [PubMed]

42. Knotek, K.; Verner, V.; Chaloupkova, P.; Kokoska, L. Prevalence and Use of Herbal Products in the Czech Republic: Over-theCounter Survey among Adult Pharmacies Clients. Complement. Ther. Med. 2012, 20, 199-206. [CrossRef]

43. Sánchez, M.; González-Burgos, E.; Iglesias, I.; Lozano, R.; Gómez-Serranillos, M.P. Current Uses and Knowledge of Medicinal Plants in the Autonomous Community of Madrid (Spain): A Descriptive Cross-Sectional Study. BMC Complement. Med. Ther. 2020, 20, 306. [CrossRef]

44. Lynch, N.; Berry, D. Differences in Perceived Risks and Benefits of Herbal, over-the-Counter Conventional, and Prescribed Conventional, Medicines, and the Implications of This for the Safe and Effective Use of Herbal Products. Complement. Ther. Med. 2007, 15, 84-91. [CrossRef]

45. Djuv, A.; Nilsen, O.G.; Steinsbekk, A. The Co-Use of Conventional Drugs and Herbs among Patients in Norwegian General Practice: A Cross-Sectional Study. BMC Complement. Altern. Med. 2013, 13, 295. [CrossRef]

46. Harnack, L.J.; DeRosier, K.L.; Rydell, S.A. Results of a Population-Based Survey of Adults' Attitudes and Beliefs about Herbal Products. J. Am. Pharm. Assoc. 2003, 43, 596-601. [CrossRef] [PubMed]

47. Clement, Y.N.; Morton-Gittens, J.; Basdeo, L.; Blades, A.; Francis, M.J.; Gomes, N.; Janjua, M.; Singh, A. Perceived Efficacy of Herbal Remedies by Users Accessing Primary Healthcare in Trinidad. BMC Complement. Altern. Med. 2007, 7, 4. [CrossRef]

48. Jang, S.; Kim, K.H.; Sun, S.-H.; Go, H.-Y.; Lee, E.-K.; Jang, B.-H.; Shin, Y.-C.; Ko, S.-G. Characteristics of Herbal Medicine Users and Adverse Events Experienced in South Korea: A Survey Study. Evid. Based Complement. Altern. Med. 2017, $2017,4089019$. [CrossRef] [PubMed]

49. Hwang, J.K.; Kim, E.-J.; Lee, S.-M.; Lee, Y.-K. Impact of Susceptibility to Global Consumer Culture on Commitment and Loyalty in Botanic Cosmetic Brands. Sustainability 2021, 13, 892. [CrossRef]

50. Pudaruth, S.; Juwaheer, T.D.; Seewoo, Y.D. Gender-Based Differences in Understanding the Purchasing Patterns of Eco-Friendly Cosmetics and Beauty Care Products in Mauritius: A Study of Female Customers. Soc. Responsib. J. 2015, 11, 179-198. [CrossRef]

51. Dimitrova, V.; Kaneva, M.; Gallucci, T. Customer Knowledge Management in the Natural Cosmetics Industry. Ind. Manag. Data Syst. 2009, 109, 1155-1165. [CrossRef]

52. Cervellon, M.-C.; Carey, L. Consumers' Perceptions of "Green": Why and How Consumers Use Eco-Fashion and Green Beauty Products. Crit. Stud. Fash. Beauty 2012, 2, 117-138. [CrossRef]

53. Kim, S.; Seock, Y.K. Impacts of Health and Environmental Consciousness on Young Female Consumers' Attitude towards and Purchase of Natural Beauty Products. Int. J. Consum. Stud. 2009, 33, 627-638. [CrossRef]

54. Chin, J.; Jiang, B.; Mufidah, I.; Persada, S.; Noer, B. The Investigation of Consumers' Behavior Intention in Using Green Skincare Products: A Pro-Environmental Behavior Model Approach. Sustainability 2018, 10, 3922. [CrossRef]

55. Mohammad, N.; Baharun, R.B. Intention to Purchase Organic Personal Care Product. Adv. Sci. Lett. 2017, 23, 7367-7369. [CrossRef]

56. Li, Y.; Shang, Y.; Yang, Y. Clustering Coefficients of Large Networks. Inf. Sci. 2017, 382-383, 350-358. [CrossRef]

57. Dharmarajan, A.; Velmurugan, T. Applications of Partition Based Clustering Algorithms: A Survey. In Proceedings of the 2013 IEEE International Conference on Computational Intelligence and Computing Research, IEEE ICCIC 2013, Madurai, India, 26-28 December 2013; IEEE Computer Society: Washington, DC, USA, 2013. [CrossRef]

58. Dziechciarz-Duda, M. Marketing Applications of Cluster Analysis to Durables Market Segmentation. Taksonomia 2007, 14, 523-532.

59. Güney, O.I. Consumption Attributes and Preferences on Medicinal and Aromatic Plants: A Consumer Segmentation Analysis. Cienc. Rural 2019, 49, 20180840. [CrossRef]

60. Sharifi, A.S.; Bazaee, G.; Abbas Heydari, S. Targeted Marketing in Herbal Medicine; Application for Grounded Theory and K-Mean Algorithm. Int. J. Agric. Manag. Dev. 2019, 9, 331-346. [CrossRef]

61. Truong, N.H. Market Segmentation for Pro-Environmental Cosmetic Products; Vaasan Ammattikorkeakoulu: Vaasa, Finland, 2016.

62. Eberhart, A.K.; Naderer, G. Quantitative and QualitativeInsights into Consumers' Sustainable Purchasing Behaviour: A Segmentation Approach Based on Motives and Heuristic Cues. J. Mark. Manag. 2017, 33, 1149-1169. [CrossRef]

63. Garcia-Alvarez, A.; Egan, B.; De Klein, S.; Dima, L.; Maggi, F.M.; Isoniemi, M.; Ribas-Barba, L.; Raats, M.M.; Meissner, E.M.; Badea, M.; et al. Usage of Plant Food Supplements across Six European Countries: Findings from the Plantlibra Consumer Survey. PLoS ONE 2014, 9, e92265. [CrossRef]

64. Greger, J.L. Dietary Supplement Use: Consumer Characteristics and Interests. J. Nutr. 2001, 131, 1339S-1343S. [CrossRef]

65. Hair, J.F.; Black, W.C.; Babin, B.J.; Anderson, R.E. Multivariate Data Analysis; Pearson Education Limited: London, UK, 2014.

66. Norusis, M.J. SPSS 12.0 Statistical Procedures Companion; Prentice Hall: Hoboken, NJ, USA, 2003.

67. Pocol, C.B.; Pinoteau, M.; Amuza, A.; Burlea-Schiopoiu, A.; Glogovețan, A.-I. Food Waste Behavior among Romanian Consumers: A Cluster Analysis. Sustainability 2020, 12, 9708. [CrossRef] 
68. Jain, A.K. Data Clustering: 50 Years beyond K-Means. Pattern Recognit. Lett. 2010, 31, 651-666. [CrossRef]

69. Using K-Means to Classify Customers-IBM Documentation. Available online: https://www.ibm.com/docs/en/spss-statistics/ 24.0.0?topic=analysis-using-means-classify-customers (accessed on 23 July 2021).

70. Cadar, R.L.; Pocol, C.B. Safety and Efficacy Assessment of Medicinal and Aromatic Plants Derived Products. A Qualitative Research. Bull. UASVM Hortic. 2020, 77, 1. [CrossRef]

71. European Commission. A European Green Deal. Available online: https://ec.europa.eu/info/strategy/priorities-2019-2024/ european-green-deal_en (accessed on 3 July 2021). 